\title{
Evaluation of Positioning Performance using the GPS + QZSS in Shanghai
}

\author{
By Yun Zhang, ${ }^{1)}$ Yongming LIU, ${ }^{2)}$ Zhonghua Hong,${ }^{1)}$ Chunming FAN ${ }^{3)}$ and Akio YASUdA ${ }^{3)}$ \\ ${ }^{1)}$ Shanghai Ocean University, Shanghai, China \\ ${ }^{2)}$ Shanghai Maritime University, Shanghai, China \\ ${ }^{3)}$ Tokyo University of Marine Science and Technology University, Tokyo, Japan
}

(Received September 27th, 2012)

\begin{abstract}
The Global Position System (GPS) may have poor performance in metropolitan areas where there is a terrible blocking effect for satellite signals. A different positioning system combination will increase the number of visible satellites and enhance the strength of the satellite geometry. The Japanese Aerospace Exploration Agency (JAXA) confirmed that the first quasi-zenith satellite (QZS) "MICHIBIKI" began providing positioning signals on June 22, 2011 (JST). The QZS system (QZSS) can provide compatible signals and has a better interoperability with GPS. Therefore, we used integration of the two systems to verify the changes in positioning performance. To demonstrate the positioning accuracy of the proposed methods, evaluations of the positioning performance using only the GPS system and the GPS + QZSS system are conducted using real observation data in Shanghai. Three indicators are used to evaluate the positioning performance: the number of visible satellites (NVS), position dilution of precision (PDOP), and root mean square (RMS). Meanwhile, the results show that GPS augmentation using the QZSS improves the positioning performance for high elevation mask angles. Positioning availability increases more than $30 \%$ at 45 degrees, and by as much as $64 \%$ on day 3 . The performance is more stable using the GPS + QZSS.
\end{abstract}

Key Words: $\quad$ GPS, QZSS, Positioning Performance, Shanghai

\section{Introduction}

Both military and civilian services have higher expectations for availability of positioning accuracy for use in fields such as automotive navigation and airplane landing. The Global Positioning System (GPS) on its own provides limited availability and unstable reliability of positioning in mountainous terrain and urban canyons. This causes inconvenience for many people, especially those living in dense cities. This situation is caused by blocking of low elevation satellite signals resulting in an insufficient number of visible satellites. Japan's quasi-zenith satellite system (QZSS) is designed to improve this situation as a regional navigation system specifically for the Asia region. The QZSS constellation is composed of three satellites in orbit. Each orbital satellite has a single orbital plane. These satellites will be placed in highly elliptical orbit (HEO). They have a common ground track which looks like asymmetric "8." Key parameters are a semi major axis of 42,164 km (average), an eccentricity of $0.075 \pm 0.015$, and an inclination of $43 \pm 4$ degrees. $^{1,2)}$ The first QZSS unit "MICHIBIKI" was launched in September 2010 from Japan. ${ }^{3)}$ Figure 1 shows the QZS ground track and the location of Shanghai and Tokyo. Due to the QZS broad track in the East Asian and Australian region, it will have an impact on the positioning performance in this area.

The Japanese Aerospace Exploration Agency (JAXA) confirmed that "MICHIBIKI" began providing positioning

(C) 2014 The Japan Society for Aeronautical and Space Sciences

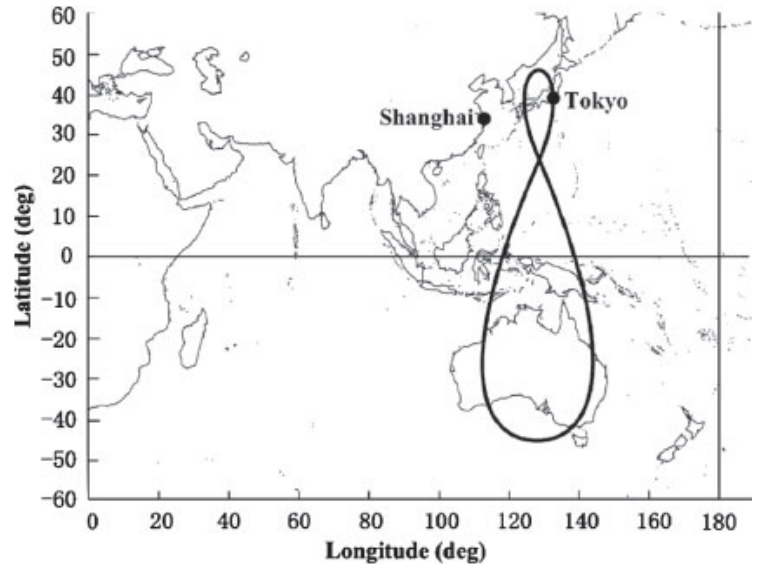

Fig. 1. QZS track on the ground and the location of Shanghai and Tokyo.

signals on June 22, 2011 (JST). ${ }^{4)}$ The QZSS provides six types of signals for users: L1C/A, L1C, L1-SAIF, L2C, L5 and LEX. C/A code on L1 for pseudorange measurement is used in this paper.

In early studies, before the "MICHIBIKI" launch, performance evaluations in Japan and the East Asian region for GPS with and without QZSS augmentation were obtained using a triple-frequency simulator. ${ }^{5-8)}$ The simulator results showed that the QZSS can improve positioning performance in the local Japan area and most of the East Asian region. In the simulator, the navigation solutions and tracking errors were generated based on theoretical models to replace errors in the real environment such as ephemeris 
Data collection and data format conversion

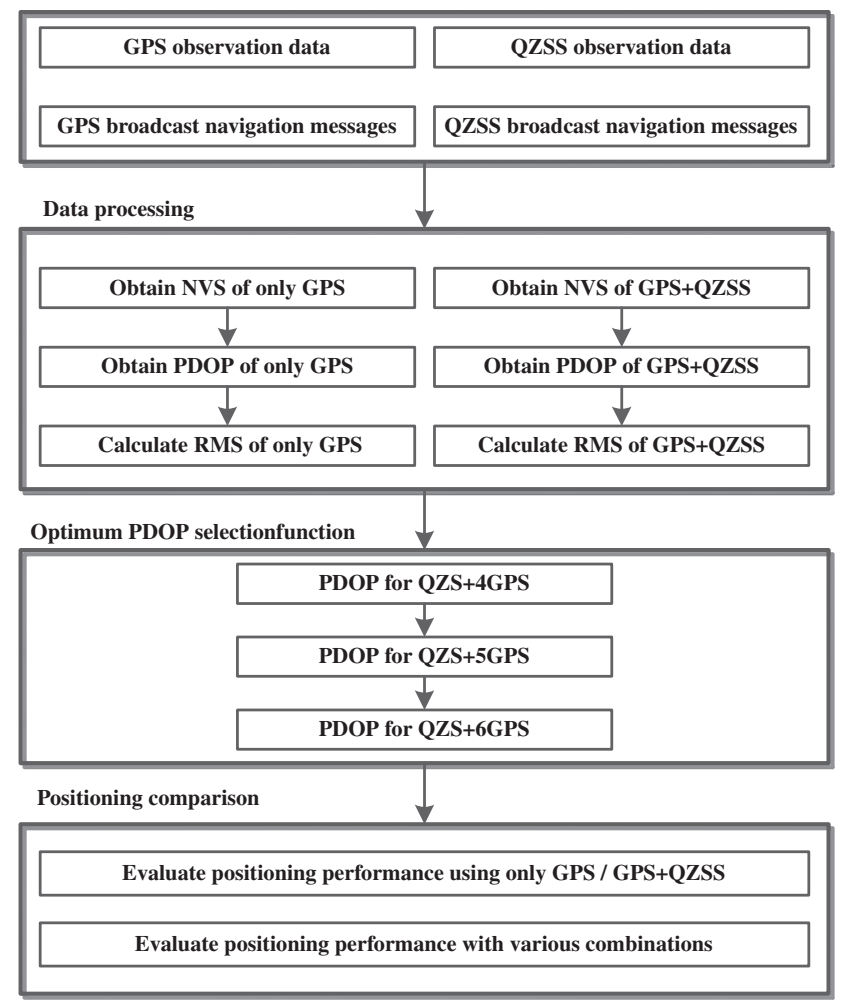

Fig. 2. Framework of positioning using combination of GPS and QZSS in Shanghai.

errors and atmospheric errors. However, some errors cannot be accurately predicted like multipath error or ephemeris error. Since the first QZS provided an available signal, some tests evaluated the overall real performance with real observed QZS data in Japan. ${ }^{9)}$ However, no evaluation test has been conducted using real data of GPS + QZSS in China so far. Shanghai has a similar urban layout to that of Tokyo and other cities in Japan. However, the location is different relative to the ground track of the QZS. Therefore, to verify the QZSS performance in regions outside of Japan, we perform this experiment using real observation data in Shanghai.

In this paper, the analysis is mainly focused on comparing the positioning performance using the QZSS + GPS system and only the GPS system in Shanghai. Different scenarios are investigated in this paper. The performance is not only evaluated for the default elevation mask angle, but also verified via simulation of severe ambient conditions through the optimum position dilution of precision (PDOP) selected. Three indicators are used to evaluate the positioning performance: the number of visible satellites (NVS), PDOP, and root mean square (RMS). ${ }^{9,10)}$

Figure 2 shows the framework of this experiment. There are four major tasks:

1) Collect data and convert data format.

2) Obtain NVS and PDOP from observation data and calculate RMS using the GPS + QZSS and the GPS only.

3) The QZS retains high elevation when observed in Shanghai, so developing the optimum PDOP selected func-
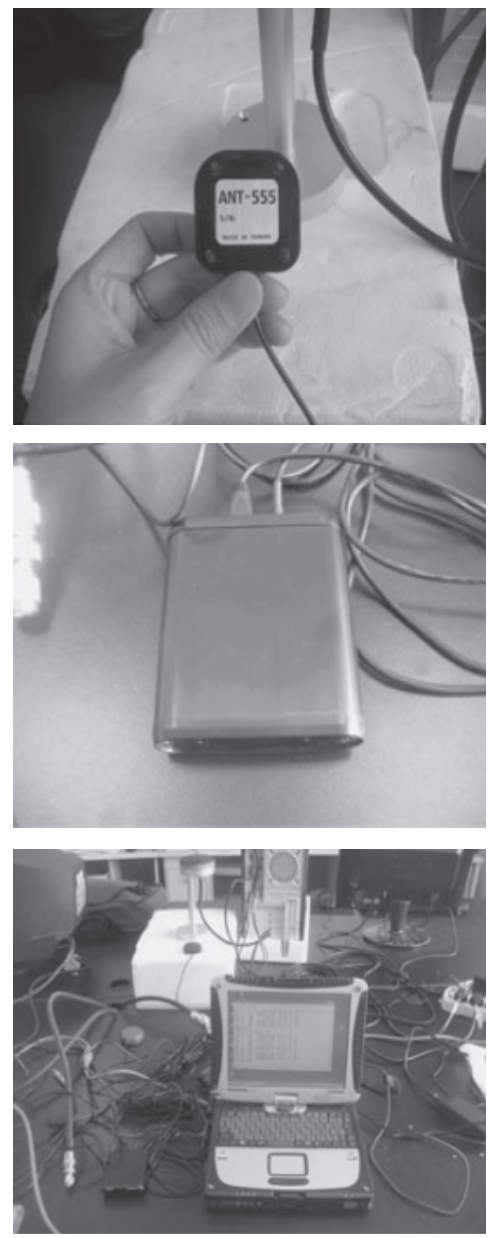

Fig. 3. Antenna of receiver (top), GPS/QZSS L1 receiver (middle) and the whole test environment (bottom).

tion to analyze positioning performance affected by the QZS. Choose four, five and six GPS satellites successively with the QZS to compare PDOP and positioning performance with that of all GPS satellites.

4) Evaluate positioning performance using only the GPS and the GPS + QZSS.

\section{Data Collection}

Figure 3 shows the antenna (top) and the receiver (middle) used in the experiment. A single frequency GPS/ QZSS receiver (OSQZSS-rk (SensorComm)) is used in this study. The receiver can obtain the GPS and QZSS L1 C/A code. The antenna of the receiver used (ANT-555) is made in Taiwan. Three worth of days real observation data in Shanghai is collected to evaluate the positioning performance. The lengths of the three data files are different. Table 1 shows detailed information about equipment, configuration and the time of observation data in this experiment. Due to a fault in the receiver, there is no observation data from 13:44:19 to $15: 09: 53$ on day 2 . The output rate of positioning data is set to $1 \mathrm{~Hz}$ to generate more statistical samples. The mask angle is set to 5, 15, 30 and 45 degrees to simulate different situations. 
Table 1. Equipment configuration and observation data length in the evaluation.

\begin{tabular}{ccc}
\hline Antenna & Receiver & Output rate \\
\hline ANT-555 & L1 GPS/QZSS receiver & $1 \mathrm{~Hz}$ \\
& (QSQZSS-rk) & \\
\hline Observation data (GPS time) & \\
Day 1 & 2012/01/05 02:54:44-2012/01/05 14:23:01 \\
Day 2 & 2012/01/06 00:33:40-2012/01/06 13:44:19 \\
& $2012 / 01 / 06 ~ 15: 09: 53-2012 / 01 / 07 ~ 01: 29: 36$ \\
Day 3 & $2012 / 01 / 0701: 30: 03-2012 / 01 / 0709: 09: 42$ \\
\hline
\end{tabular}

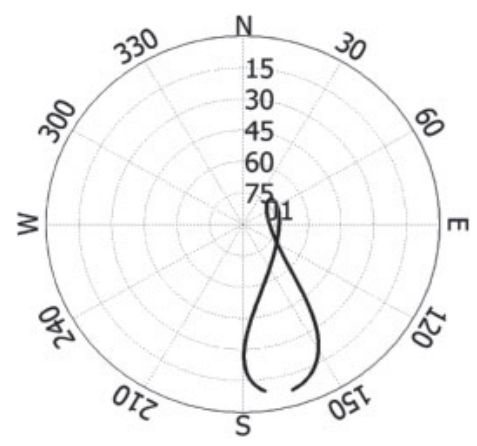

Fig. 4. QZSS skyplot in Shanghai.

\section{QZS Track}

Shanghai has similar urban conditions to many of Japan's cities and is located close to the QZS orbital region. Figure 4 shows the QZS skyplot observed in Shanghai $\left(30^{\circ} 53^{\prime} \mathrm{N}\right.$, $121^{\circ} 53^{\prime} \mathrm{E}$ ) on day 2 . It can be seen from Fig. 4 that the QZS-1 track is an asymmetric figure 8. The azimuth ranges from 45 to 180 degrees.

Figure 5 shows the temporal variation of elevation angle that varies from 8 to 78 degrees on day 2 in Shanghai. From the figure, we can see that the QZS stays for more than eight hours at an elevation of 70 degrees. If there are three satellites in orbit, at least one QZS will have its zenith over Shanghai.

Figure 6 shows the signal-to-noise ratios (SNR) for the L1 signal of the QZSS and the GPS on day 2. Since the elevation angle of QZS-1 varies from 8 to 78 degrees, the output elevation of the two systems is set in this range. The GPS uses 31 satellites' observation data while the QZSS uses only one satellite's observation data. We can see from Fig. 6 that the C/A code signals of the GPS are $1-4 \mathrm{~dB}$ more powerful than the signal of QZS-1 ("MICHIBIKI") over the elevation range.

\section{Pseudorange Measurement}

The GPS/QZSS receiver can receive the L1 C/A code with the SNR information. The distance from satellite to receiver is measured by the observation equation of Eq. (1).

$$
\rho^{s}=r+\delta_{t u}-\delta_{t}^{s}+I+T+\varepsilon_{\rho}
$$

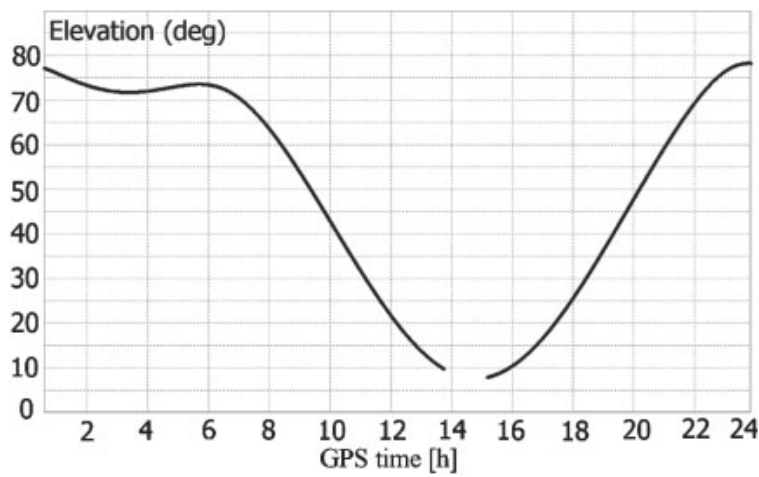

Fig. 5. Elevation angle temporal variations of the first QZSS unit "MICHIBIKI" in Shanghai.

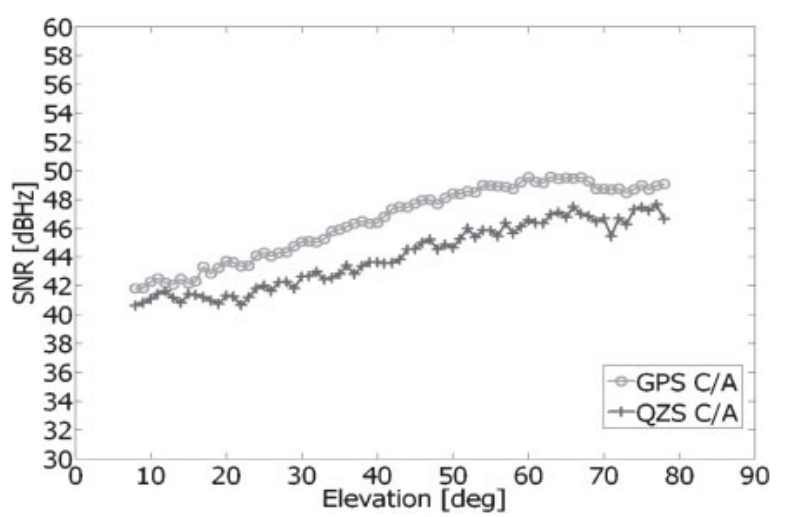

Fig. 6. SNRs for the QZSS L1 signal and the GPS L1 signal on day 2.

where $\rho^{s}$ is the pseudorange, $r$ is the geometric distance from satellite $s$ to receiver $u, \delta_{t u}$ and $\delta_{t}^{s}$ are the receiver clock error and the satellite clock error, respectively, $I$ is the ionosphere delay on L1 frequency, $T$ is the troposphere delay and $\varepsilon_{\rho}$ is the noise on pseudorange. ${ }^{11)}$ In this study, the ionosphere delay is estimated using the Klobuchar model. The Klobuchar model has a relatively simple model formula. The required parameter can be obtained from broadcast ephemeris and the input data can be calculated conveniently for single frequency receiver. Subsequently the Saastamoinen model is used to estimate the troposphere delay.

The RTKLIB software is used to process observation data in this study. It is an open source program for GNSS positioning which can handle RINEX observation data for the GPS, GLONASS, Galileo and the QZSS. ${ }^{12)}$ Based on this open source, because of the QZSS high elevation feature, we added the optimum PDOP selection function to evaluate positioning performance with the QZSS and fewer GPS satellites. First, according to the different visible time of GPS, we choose all groups of four GPS satellites with one QZS. Finding the best group of PDOP with 4GPS + QZSS, we then add one GPS satellite from the rest of the satellites, and find the best group of PDOP with 5GPS + QZSS. According to the above method, we add another GPS satellite again, and find the best group of PDOP with 6GPS + QZSS. All solution data is obtained in the stand-alone positioning mode in the next tests. 
Table 2. NVS and positioning availability for different elevation angles.

\begin{tabular}{|c|c|c|c|c|c|}
\hline $\begin{array}{l}\text { Mask } \\
\text { angle }\end{array}$ & System & Max. & Min. & Mean & $\begin{array}{l}\text { Availability } \\
(\mathrm{NVS} \geqslant 4)\end{array}$ \\
\hline \multicolumn{6}{|l|}{ Day 1} \\
\hline \multirow[t]{2}{*}{5} & GPS only & 11 & 7 & 9.2 & $100 \%$ \\
\hline & QZSS + GPS & 12 & 8 & 10.2 & $100 \%$ \\
\hline \multirow[t]{2}{*}{15} & GPS only & 9 & 5 & 7.4 & $100 \%$ \\
\hline & QZSS + GPS & 10 & 6 & 8.2 & $100 \%$ \\
\hline \multirow[t]{2}{*}{30} & GPS only & 7 & 3 & 5.1 & $98.8 \%$ \\
\hline & QZSS + GPS & 8 & 4 & 5.8 & $100 \%$ \\
\hline \multirow[t]{2}{*}{45} & GPS only & 5 & 2 & 3.2 & $32.9 \%$ \\
\hline & QZSS + GPS & 6 & 2 & 3.6 & $65.2 \%$ \\
\hline \multicolumn{6}{|l|}{ Day 2} \\
\hline \multirow[t]{2}{*}{5} & GPS only & 11 & 7 & 9.3 & $100 \%$ \\
\hline & QZSS + GPS & 12 & 8 & 10.3 & $100 \%$ \\
\hline \multirow[t]{2}{*}{15} & GPS only & 9 & 5 & 7.5 & $100 \%$ \\
\hline & QZSS + GPS & 10 & 6 & 8.4 & $100 \%$ \\
\hline \multirow[t]{2}{*}{30} & GPS only & 8 & 3 & 5.1 & $98.2 \%$ \\
\hline & QZSS + GPS & 8 & 4 & 5.9 & $100 \%$ \\
\hline \multirow[t]{2}{*}{45} & GPS only & 5 & 1 & 3.2 & $29.4 \%$ \\
\hline & QZSS + GPS & 6 & 2 & 3.8 & $65.6 \%$ \\
\hline \multicolumn{6}{|l|}{ Day 3} \\
\hline \multirow[t]{2}{*}{5} & GPS only & 11 & 7 & 9.3 & $100 \%$ \\
\hline & QZSS + GPS & 12 & 8 & 10.3 & $100 \%$ \\
\hline \multirow[t]{2}{*}{15} & GPS only & 9 & 5 & 7.5 & $100 \%$ \\
\hline & QZSS + GPS & 10 & 6 & 8.5 & $100 \%$ \\
\hline \multirow[t]{2}{*}{30} & GPS only & 6 & 3 & 4.8 & $94.1 \%$ \\
\hline & QZSS + GPS & 7 & 4 & 5.8 & $100 \%$ \\
\hline \multirow[t]{2}{*}{45} & GPS only & 4 & 2 & 3.1 & $21.6 \%$ \\
\hline & $\mathrm{QZSS}+\mathrm{GPS}$ & 5 & 3 & 4.1 & $85.6 \%$ \\
\hline
\end{tabular}

\section{NVS}

NVS is an important indicator of positioning performance since the positioning function can be used only when we receive more than four visible satellites. In this way, more visible satellites mean more positioning functions, and the solution can be improved. Thus, NVS is related to the positioning availability.

Table 2 shows the NVS and positioning availability for different mask angles. The NVS using QZSS + GPS has approximately one more satellite on average than only the GPS system on the three days. As mask angle increases, the availability improves greatly. At 45 degrees, the improvement using GPS + QZSS reaches approximately $32.3 \%$ on day $1,36.2 \%$ on day 2 , and $64 \%$ on day 3 . We can conclude that the augmentation system using QZSS greatly benefits positioning availability in Shanghai, especially with high mask angle.

\section{PDOP}

In Eq. (1), $r$ represents the distance from satellite $s$ to the receiver as shown in Eq. (2). Linearizing the nonlinear equations, we obtain Eq. (3) as follows. ${ }^{13)}$

$$
\begin{gathered}
r=\left\|x^{s}-x\right\|=\sqrt{\left(x^{s}-x\right)^{2}-\left(y^{s}-y\right)^{2}-\left(z^{s}-z\right)^{2}} \\
\boldsymbol{G}\left[\begin{array}{c}
\Delta x+\varepsilon_{x} \\
\Delta y+\varepsilon_{y} \\
\Delta z+\varepsilon_{z} \\
\Delta \delta_{t}+\varepsilon_{\delta_{t}}
\end{array}\right]=\boldsymbol{b}+\boldsymbol{\varepsilon}_{\rho}
\end{gathered}
$$

where $\boldsymbol{G}$ is the geometric matrix, $\boldsymbol{b}$ is the vector of predicted minus actual code measurement, $\Delta x, \Delta y, \Delta z$ are the position error between adjacent observation time, $\Delta \delta_{t}$ is the receiver clock error, $\boldsymbol{\varepsilon}_{\rho}$ is the vector of measurement error and $\varepsilon_{x}, \varepsilon_{y}$, $\varepsilon_{z}, \varepsilon_{\delta_{t}}$ are the positioning error caused by $\boldsymbol{\varepsilon}_{\rho}$.

PDOP is the indicator of positioning accuracy. PDOP depends on the weight coefficient matrix, $\boldsymbol{H}=\left(\boldsymbol{G}^{\mathrm{T}} \boldsymbol{G}\right)^{-1}$. It is the mathematical quality of solutions predicted by calculating the position of each satellite relative to other satellites in the constellation. The smaller value indicates a higher probability of better satellite geometry position and more accurate positioning performance. The standard deviation of positioning error in space depends on the PDOP, as in Eq. (4).

$$
\sigma_{P}=\mathrm{PDOP} \cdot \sigma_{U R E}
$$

where $\sigma_{U R E}$ is the standard deviation of range measurement error and $\sigma_{P}$ is the standard deviation of three-dimensional space positioning error. ${ }^{14)}$

Figure 7 shows the temporal variations of PDOP and NVS using only the GPS and the QZSS + GPS with different elevation mask degrees on day 2. The left longitudinal axis represents the strength of PDOP as shown by the black line. The right longitudinal axis shows the NVS as shown by the gray line. There is no PDOP value for which NVS is less than 4 . The PDOP does not show a significant improvement for parts (a) and (b) at 5 degrees. The improvement of PDOP can be seen in parts (c) and (d) when the QZS is visible and the NVS is small. The improvement is magnified in (e), (f), (g) and (h) with the increasing mask angle. It can be seen that there is not only improvement in PDOP, but also improvement in availability after integrating the QZS.

Table 3 lists the minimum, maximum and mean of PDOP in two systems at different mask angles on day 2. Only a PDOP of less than 10 is used. The PDOP always becomes larger with increasing mask angle and the value of the GPS only is always larger than GPS + QZSS. The maximum of PDOP reaches the available PDOP boundary of 10.00 in GPS only on day 1 and day 2.

\section{Accuracy and Precision}

Accuracy and precision represent the strength of system measurement error and random measurement error. Precision reflects the stability of positioning performance. Accuracy can be estimated by the measurement results minus actual location and precision can be calculated by RMS of positioning results. Small values represent stable 

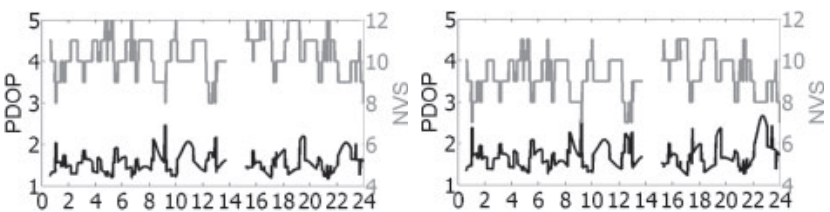

(a) GPS+QZS at 5 degrees

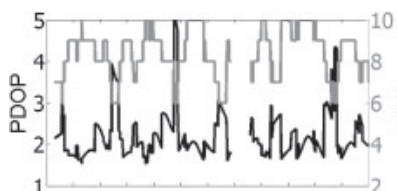

02468101214161820222

(c) GPS+QZS at 15 degrees

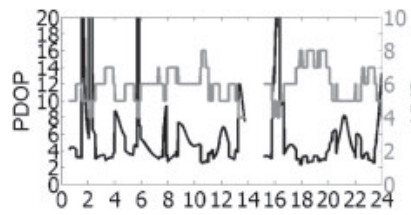

(e) GPS+QZS at 30 degrees

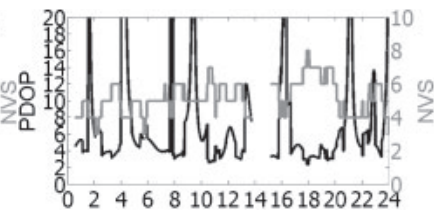

(f) GPS only at 30 degrees

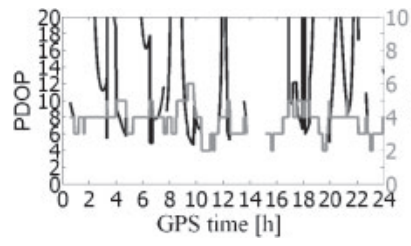

(g) GPS+QZS at 45 degrees

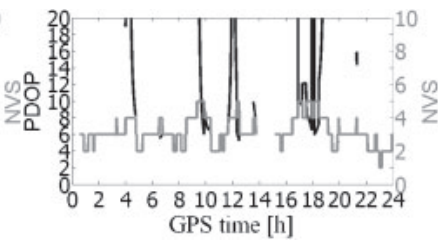

(h) GPS only at 45 degrees

Fig. 7. Temporal variations of the PDOP and NVS using only the GPS and the QZSS + GPS with different elevation mask degrees on day 2.

positioning performance. ${ }^{15-17)}$ Figure 8 shows positioning errors and random errors between positioning points and real location epoch with different mask angles in latitude, longitude and height on day 2. Black points show the results using GPS + QZSS and grey points represent the results using GPS only. The black points are completely covered by gray points from (a) and (b). This indicates no obvious difference in availability between using the GPS + QZSS and using the GPS only at 5 and 15 degrees. In (c) and (d), there are clearly more black points than grey points. This indicates that available positioning time is obviously improved after integrating the QZS for higher mask angles. The QZSS can improve positioning performance in urban situations.

Table 4 lists the variations of RMS with different mask angles in latitude, longitude and height in three days. As for the analysis results of PDOP, accuracy can be improved for different mask angle cases. The accuracy improves greatly as mask angle increases. Due to the asymmetric distribution of visible satellites relative to the ground in three-dimensional space, the RMS value of height is always larger than the value of latitude and longitude, and the RMS value of longitude is lowest. The positioning performance becomes unstable and the difference of RMS between the QZSS + GPS and the GPS becomes larger with increasing elevation mask angle in the two systems. RMS error using the QZSS + GPS in three directions is less than using only
Table 3. The maximum, minimum and mean of PDOP on day 1 , day 2 and day 3 .

\begin{tabular}{|c|c|c|c|c|}
\hline Mask angle & System & Max. & Min. & Mean \\
\hline \multicolumn{5}{|c|}{ Day $1(\mathrm{PDOP} \leqslant 10)$} \\
\hline \multirow[t]{2}{*}{5} & GPS only & 2.581 & 1.270 & 1.666 \\
\hline & QZSS + GPS & 2.471 & 1.181 & 1.564 \\
\hline \multirow[t]{2}{*}{15} & GPS only & 10.00 & 1.605 & 2.393 \\
\hline & QZSS + GPS & 5.369 & 1.533 & 2.200 \\
\hline \multirow[t]{2}{*}{30} & GPS only & 10.00 & 2.549 & 4.693 \\
\hline & QZSS + GPS & 10.00 & 2.507 & 4.528 \\
\hline \multirow[t]{2}{*}{45} & GPS only & 10.00 & 5.246 & 7.245 \\
\hline & QZSS + GPS & 10.00 & 4.653 & 7.142 \\
\hline \multicolumn{5}{|c|}{ Day $2(\mathrm{PDOP} \leqslant 10)$} \\
\hline \multirow[t]{2}{*}{5} & GPS only & 2.665 & 1.224 & 1.682 \\
\hline & QZSS + GPS & 2.470 & 1.164 & 1.556 \\
\hline \multirow[t]{2}{*}{15} & GPS only & 10.00 & 1.605 & 2.452 \\
\hline & QZSS + GPS & 5.374 & 1.530 & 2.179 \\
\hline \multirow[t]{2}{*}{30} & GPS only & 10.00 & 2.345 & 4.731 \\
\hline & QZSS + GPS & 10.00 & 2.345 & 4.479 \\
\hline \multirow[t]{2}{*}{45} & GPS only & 10.00 & 5.084 & 7.510 \\
\hline & QZSS + GPS & 10.00 & 4.658 & 7.513 \\
\hline \multicolumn{5}{|c|}{ Day $3(\mathrm{PDOP} \leqslant 10)$} \\
\hline \multirow[t]{2}{*}{5} & GPS only & 2.578 & 1.271 & 1.641 \\
\hline & QZSS + GPS & 2.469 & 1.180 & 1.523 \\
\hline \multirow[t]{2}{*}{15} & GPS only & 5.760 & 1.616 & 2.282 \\
\hline & QZSS + GPS & 3.935 & 1.531 & 2.064 \\
\hline \multirow[t]{2}{*}{30} & GPS only & 10.00 & 2.987 & 4.753 \\
\hline & QZSS + GPS & 10.00 & 2.670 & 4.602 \\
\hline \multirow[t]{2}{*}{45} & GPS only & 10.00 & 5.544 & 6.822 \\
\hline & QZSS + GPS & 10.00 & 4.859 & 7.553 \\
\hline
\end{tabular}

the GPS. It indicates that using this augmentation system positioning is more stable.

\section{Optimum PDOP Selected with QZSS}

From the above depiction, we can see that QZS has high elevation ( $\geqslant 70$ degree) in Shanghai for more than eight hours. It gives us chance to get better positioning performance with the QZSS and fewer GPS satellites. We added the optimum PDOP selection function to evaluate positioning performance with the QZSS and fewer GPS satellites.

Figure 9 shows the process of the optimum PDOP selected with the QZSS from the epoch of 5:30 to 7:00 (GPST) on day 3. There are nine visible GPS satellites with PRN numbers of 2, 4, 5, 7, 8, 10, 15, 26 and 29. We remove the PRN 7 satellite because its elevation ranges from 5 to 13 degrees during the chosen time. First, according to the different visible time of the GPS satellites, we choose 23 groups of four GPS satellites from all visible satellites to integrate with the QZSS. The optimal combination in PDOP from 23 groups is the group with PRN numbers of 4, 8, 15 and 29 with QZSS. Then, we add one GPS satellite from the rest of the satellites and calculate the PDOP value. The suitable GPS satellite number is 5. According to the 


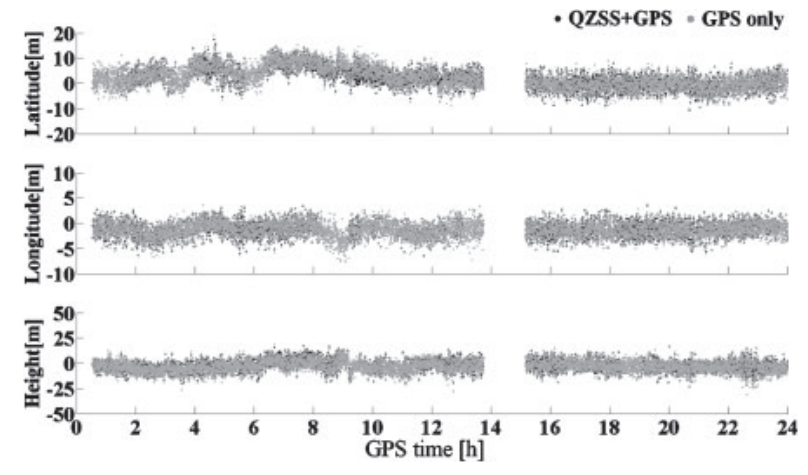

(a) 5 degrees

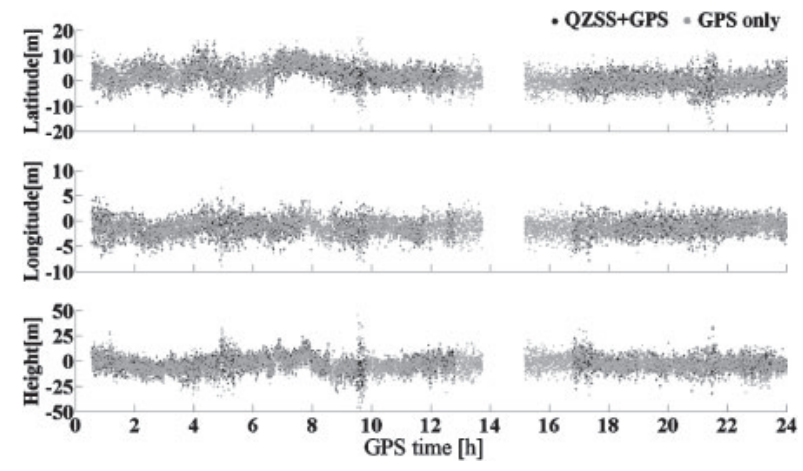

(b) 15 degrees
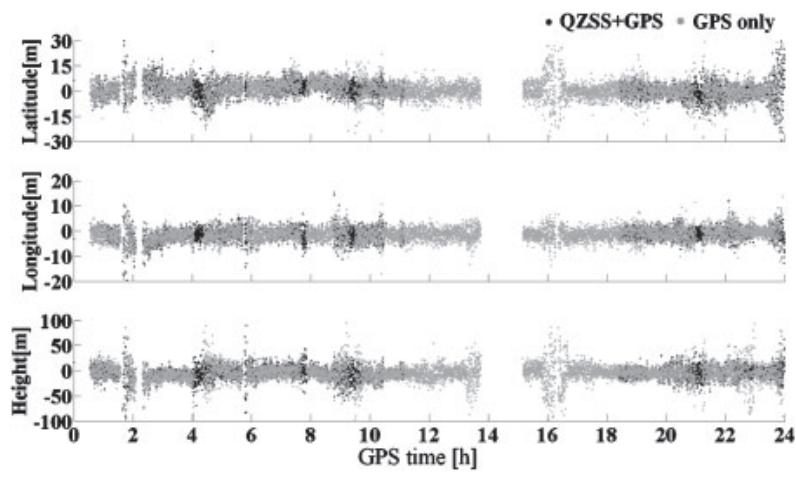

(c) 30 degrees
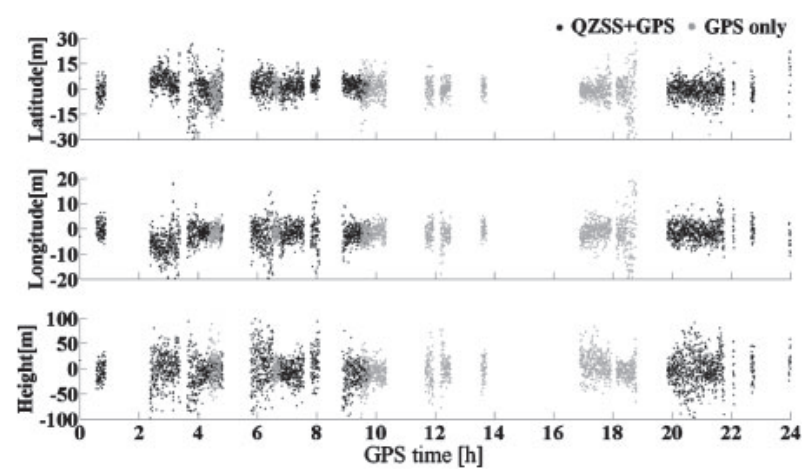

(d) 45 degrees

Fig. 8. Positioning errors and random errors between positioning points and real location epoch with different mask angle in latitude, longitude and height on day 2 .

above method, we add another GPS satellite again and obtain a GPS satellite number of 26 .

Figure 10 displays temporal variations of the PDOP with four kinds of GPS + QZSS combinations (GPS ALL,
Table 4. Variations of RMS on days 1, 2 and 3 (Lat: latitude, Lon: longitude, H: height).

\begin{tabular}{|c|c|c|c|c|}
\hline \multirow{2}{*}{$\begin{array}{l}\text { Elevation } \\
\text { (deg) }\end{array}$} & \multirow{2}{*}{ System } & \multicolumn{3}{|c|}{ RMS (m) } \\
\hline & & Lat & Lon & $\mathrm{H}$ \\
\hline \multicolumn{5}{|l|}{ Day 1} \\
\hline \multirow[t]{2}{*}{5} & QZSS + GPS & 3.133 & 1.538 & 5.356 \\
\hline & GPS only & 3.338 & 1.554 & 5.648 \\
\hline \multirow[t]{2}{*}{15} & $\mathrm{QZSS}+\mathrm{GPS}$ & 3.230 & 1.646 & 6.987 \\
\hline & GPS only & 3.771 & 1.708 & 8.705 \\
\hline \multirow[t]{2}{*}{30} & QZSS + GPS & 3.867 & 2.236 & 13.43 \\
\hline & GPS only & 4.985 & 2.479 & 16.12 \\
\hline \multirow[t]{2}{*}{45} & $\mathrm{QZSS}+\mathrm{GPS}$ & 5.180 & 2.916 & 20.01 \\
\hline & GPS only & 6.711 & 3.069 & 26.17 \\
\hline \multicolumn{5}{|l|}{ Day 2} \\
\hline \multirow[t]{2}{*}{5} & $\mathrm{QZSS}+\mathrm{GPS}$ & 3.757 & 1.474 & 5.206 \\
\hline & GPS only & 4.078 & 1.511 & 5.586 \\
\hline \multirow[t]{2}{*}{15} & QZSS + GPS & 3.588 & 1.610 & 6.928 \\
\hline & GPS only & 4.026 & 1.686 & 8.397 \\
\hline \multirow[t]{2}{*}{30} & $\mathrm{QZSS}+\mathrm{GPS}$ & 5.040 & 2.514 & 16.25 \\
\hline & GPS only & 5.931 & 2.763 & 19.01 \\
\hline \multirow[t]{2}{*}{45} & QZSS + GPS & 7.704 & 6.116 & 20.41 \\
\hline & GPS only & 12.04 & 6.165 & 23.99 \\
\hline \multicolumn{5}{|l|}{ Day 3} \\
\hline \multirow[t]{2}{*}{5} & $\mathrm{QZSS}+\mathrm{GPS}$ & 2.926 & 1.439 & 4.651 \\
\hline & GPS only & 3.014 & 1.466 & 5.063 \\
\hline \multirow[t]{2}{*}{15} & QZSS + GPS & 3.071 & 1.567 & 5.876 \\
\hline & GPS only & 3.274 & 1.635 & 6.794 \\
\hline \multirow[t]{2}{*}{30} & QZSS + GPS & 4.489 & 2.881 & 16.25 \\
\hline & GPS only & 5.279 & 2.991 & 19.33 \\
\hline \multirow[t]{2}{*}{45} & QZSS + GPS & 5.835 & 2.156 & 13.61 \\
\hline & GPS only & 8.104 & 2.668 & 26.69 \\
\hline
\end{tabular}

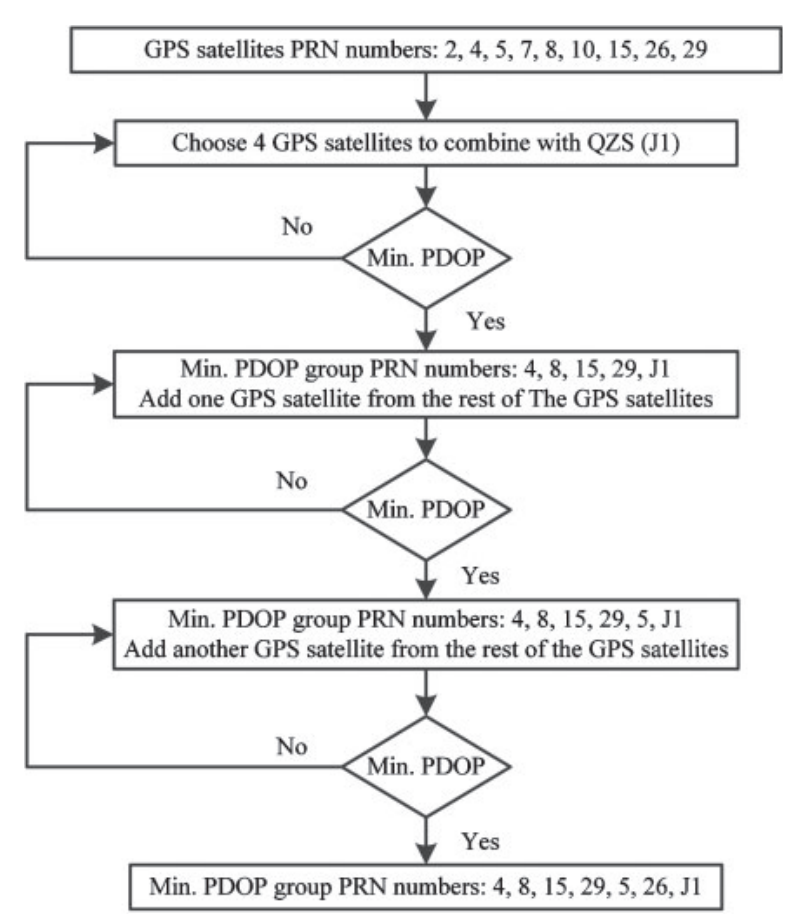

Fig. 9. Process of choosing optimum PDOP with QZSS at the epoch of 6:00 (GPST) on day 3. 

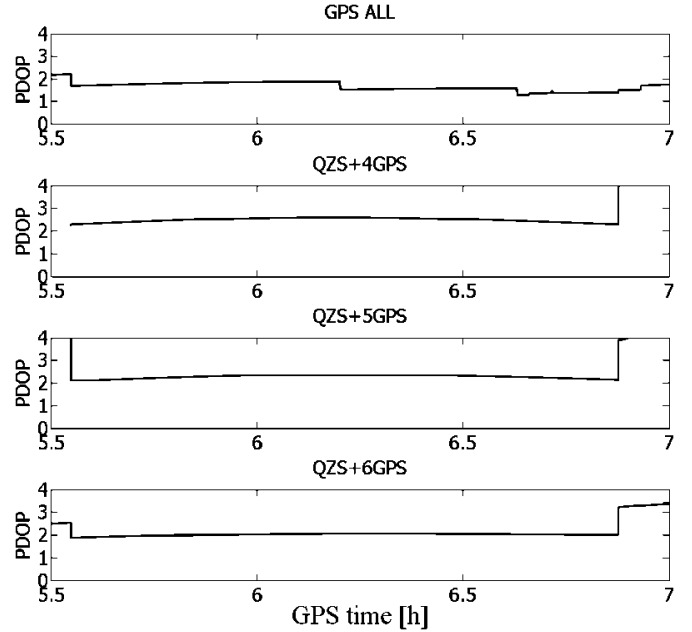

Fig. 10. Temporal variations of the PDOP with four kinds of GPS + QZSS combinations from 5:30 to 7:00 (GPST) on day 3.

Table 5. RMS of latitude, longitude, height and horizontal from 5:30 to 7:00 (GPST) on day 3 (Lat: latitude, Lon: longitude).

\begin{tabular}{lcccc}
\hline & $\begin{array}{c}\text { Lat } \\
(\mathrm{m})\end{array}$ & $\begin{array}{c}\text { Lon } \\
(\mathrm{m})\end{array}$ & $\begin{array}{c}\text { Horizontal } \\
(\mathrm{m})\end{array}$ & $\begin{array}{c}\text { Height } \\
(\mathrm{m})\end{array}$ \\
\hline All GPS & 5.274 & 1.396 & 5.456 & 5.636 \\
QZS + 4GPS & 6.901 & 1.533 & 7.070 & 6.768 \\
QZS + 5GPS & 5.024 & 1.538 & 5.254 & 6.456 \\
QZS + 6GPS & 4.660 & 1.504 & 4.897 & 5.682 \\
QZS + ALL GPS & 3.029 & 1.329 & 3.308 & 4.165 \\
\hline
\end{tabular}

QZSS + 4GPS, QZSS + 5GPS, QZSS + 6GPS) from 5:30 to 7:00 (GPST) on day 3. QZSS + 4GPS, QZSS + 5GPS, QZSS + 6GPS combinations are chosen from the optimum PDOP selection function. The above figure shows the PDOP of all nine visible GPS satellites. The second figure shows the PDOP of QZS with four GPS satellites with PRN numbers of 4, 8, 15 and 29. The third figure shows the PDOP of QZS with five GPS satellites with PRN numbers of 4, 5, 8, 15 and 29. The bottom figure shows the PDOP of QZS with six GPS satellites with PRN numbers of 4, 8, 15, 29, 5 and 26. We can see the PDOP in the three figures on the bottom is close to the PDOP in the first figure from 5:30 to 7:00 (GPST). We then analyze the horizontal deviation and vertical deviation with these four combinations during this time.

Figure 11 shows the horizontal and vertical deviation with four kinds of GPS + QZSS combinations (GPS ALL, QZSS + 4GPS, QZSS + 5GPS, QZSS + 6GPS) from 5:30 to 7:00 (GPST) on day 3. The black line illustrates the deviation of all GPS satellites and gray line shows the deviation of the QZS with different numbers of GPS satellites. The horizontal deviation and vertical deviation of QZS + 4GPS is larger than all GPS satellites in the first figure. These deviations decline as the number of GPS satellites increases and QZS + 6GPS is close to all GPS satellites. Even the horizontal deviation of QZS + 6GPS is less than all GPS satellites from 6:20 to 6:30 (GPST). Table 5 lists
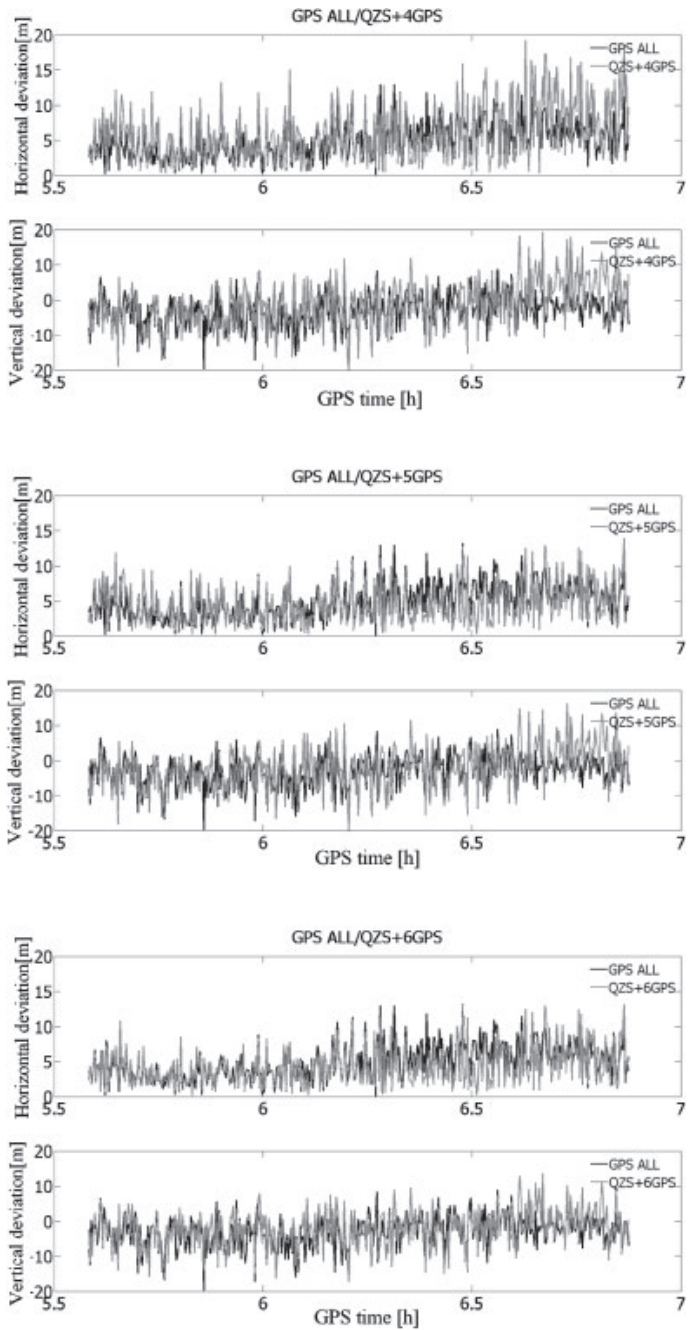

Fig. 11. Horizontal and vertical deviation with four kinds of GPS + QZSS combinations from 5:30 to 7:00 (GPST) on day 3.

the RMS of latitude, longitude, height and horizontal from 5:30 to 7:00 (GPST) on day 3 and illustrates the changes in details. Notably, the deviation of QZS + 6GPS is better than all GPS satellites in the RMS of the horizontal deviation. It indicates that positioning results of the QZS combined with suitable fewer numbers of GPS satellites can be close to or better than all GPS satellites.

\section{Conclusion}

This paper described a numerical analysis of the positioning performance using the GPS + QZSS in Shanghai. The positioning performance was analyzed for different scenarios of the GPS only and the GPS + QZSS system.

The QZS remained at over 70 degrees for more than eight hours on all measurement days. Comparing the positioning performance using the GPS + QZSS and the GPS only, the results indicated that positioning availability using GPS + QZSS was better than only the GPS system in NVS, PDOP and accuracy, especially for high mask angle. It can be concluded that GPS augmentation using the QZSS improves the availability and stability, especially under the urban environment in Shanghai. Due to its high elevation, the QZS 
can retain a stable high-quality positioning signal. The suitable fewer number of GPS satellites integrated with the QZS can attain approximately the same or better positioning performance than that of all GPS satellites. This means that the QZS not only increases the selectively of visible satellites, but also possibly improves positioning performance in harsh environments.

In the future, we will carry out more tests to evaluate Real-time-kinematic (RTK) performance with several GPS/QZSS receivers in more big cities in China.

\section{Acknowledgments}

This research was supported by the National Natural Science Foundation of China (Grant No. 41376178), Shanghai Science and Technology Committee (Project 11510501300), and the Program for Professors of Special Appointment (Eastern Scholar) at Shanghai Institutions of Higher Learning.

The authors would like to thank Mr. Tomoji Takasu, Tokyo University of Marine Science and Technology University, Japan, for his discussion on QZSS data processing and Mr. Harumasa Hojo, SensorComm Co. Ltd., for his discussion on the OSQZSSrk receiver.

\section{References}

1) Japan Aerospace Exploration Agency: Quasi-Zenith Satellite System Navigation Service Interface Specification for QZSS (IS-QZSS) V1.1, 2009.

2) QZSS Almanac Information, http://qz-vision.jaxa.jp/USE/archives/ almanac/2012/q2012005.alm

3) Launch Result of the First Quasi-Zenith Satellites "MICHIBIKI" by H-IIA Launch Vehicle No. 18, http://www.jaxa.jp/press/2010/09/ 20100911_h2af18_e.html
4) First Quasi-Zenith Satellite 'MICHIBIKI' Begins Providing Positioning Signals, http://www.jaxa.jp/press/2011/06/20110622_michibiki_e. html

5) Wu, F., Kubo, N. and Yasuda, A.: Performance Evaluation of GPS Augmentation Using Quasi-Zenith Satellites System, IEEE Trans. Aerospace Electr. Syst., 40, 4 (2004), pp. 1249-1261.

6) Zhang, Y., Kubo, N. and Yasuda, A.: The Benefit from Triple Frequencies in Ambiguity Resolution, J. Jpn. Inst. Navigation, 112 (2005), pp. 219-227.

7) Zhang, Y.: Performance Analysis of GPS Augmentation Using QuasiZenith Satellite System in Local Japan Area, ION GNSS 19th International Technical Meeting of the Satellite Division, Fort Worth, USA, 2006.

8) Zhang, Y., Wu, F. and Yasuda, A.: Impact of Integrated GPS and the Quasi-Zenith Satellite System in the East Asian Region, Trans. Jpn. Soc. Aeronaut. Space Sci., 50 (2007), pp. 105-112.

9) Kubo, N., Shirai, T., Takasu, T., Yasuda, A. and Kogure, S.: Performance Evaluation of the Effect of QZS (Quasi-Zenith Satellite) on Precise Positioning, Coordinates, 7, 7 (2011), pp. 7-13.

10) Wu, F., Kubo, N. and Yasuda, A.: Performance Analysis of GPS Augmentation using Japanese Quasi-Zenith Satellite System, Earth Planets Space, 56 (2004), pp. 25-37.

11) Misra, P. and Enge, P.: Global Positioning System, Signals, Measurements, and Performance, Ganga-Jamuna Press, Lincoln, 2001.

12) RTKLIB: An Open Source Program Package for GNSS Positioning, http://gpspp.sakura.ne.jp/rtklib/rtklib.htm

13) Xie, G.: Principles of GPS and Receiver Design, Publishing House of Electronics Industry, Beijing, 2009.

14) Kaplan, E. D. and Hegarty, C J.: Understanding GPS Principles and Applications, Artech House Publishers, London, 2005.

15) Tsujino, T.: Effectiveness of the Quasi-Zenith Satellite System in Ubiquitous Positioning, Sci. Technol. Trends, 16 (2005), pp. 88-101.

16) Takasu, T., Ebinuma, T. and Yasuda, A.: Effect of Quasi Zenith Satellite (QZS) on GPS Positioning, Proceedings of 2009 International Symposium on GPS/GNSS, Jeju, Korea.

17) Sakai, T., Fukushima, S., Takeichi, N. and Ito, K.: Augmentation Performance of QZSS L1-SAIF Signal, Proc. ION National Technical Meeting (ION NTM), San Diego, CA, 2007, pp. 411-421. 